\title{
Cena musical paulistana dos anos 2010 e o "novo artista da música" na produção independente brasileira pós-internet
}

\author{
THIAGO GALLETTA*
}

\begin{abstract}
RESUMO: Partindo de entrevistas com artistas e analisando a importância da cena musical paulistana dos anos 2010, enquanto proeminente polo criativo na música brasileira atual, o artigo discute algumas das principais reconfigurações que se operam - a partir do contexto digital recente - nos lugares ocupados pelos artistas e pelas cenas "independentes" na cadeia de produção e consumo musical. Serão analisados ainda, especialmente, os papéis simultâneos assumidos por estes artistas no cenário tecnológico e econômico emergente, enquanto "criadores" de sua obra e como "gestores" e "comunicadores" de suas carreiras. Aqui se sublinhará tanto os novos potenciais produtivos e estéticos descortinados em meio a estas mudanças, como também tensões entre estas atribuições e funções concomitantes, que não conviviam de modo tão imbricado em décadas anteriores.
\end{abstract}

PALAVRAS-CHAVE: Música Brasileira; Internet; Indústria Fonográfica; Tecnologia; Produção Independente.

\section{São Paulo musical scene in the 2010s and the "new musical artists" in Brazilian post-Internet independent production}

\begin{abstract}
Based on interviews with musicians, this article analyzes the importance of the musical scene in the 2010s in São Paulo, which is a major center of creation of current Brazilian music. The article discusses some of the major changes taking place - in view of the recent digital context - along the chain of musical production and consumption, both in the spaces occupied by independent musicians and in those occupied by independent scenes. The author analyzes the simultaneous roles played by these musicians in the emerging technological and economic scene, as "creators" of their works and as "managers" and "communicators" of their careers. Attention is given here to both the new productive and aesthetic potentials that are opening up in the midst of these changes, as well as to the tensions involving these parallel attributions and functions, which had not operated as closely together in earlier decades.
\end{abstract}

KEYWORDS: Brazilian Music; Internet; Recording Industry; Technology; Independent Production.

\footnotetext{
*Thiago Galletta é Doutorando e Mestre em Sociologia pela Unicamp. Publicou em 2016 o livro Cena Musical Paulistana dos Anos 2010: a "música brasileira" depois da internet (Annablume Editora/FAPESP). Há cerca de quinze anos desenvolve trabalhos como DJ, radialista, pesquisador musical e produtor cultural. Trabalhou por vários anos em atividades de docência e implementação de projetos junto ao Núcleo de Comunicação e Educação da ECA/USP. E-mail: djgalletta@gmail.com
}

GALLETTA, T. Cena musical paulistana dos anos 2010 e o "novo artista da música" na produção independente brasileira pós-internet. Música Popular em Revista, Campinas, ano 5, v. 2, p. 116-141, jan.jul. 2018. 
e, no contexto brasileiro, o chamado fenômeno fonográfico independente ${ }^{1}$ tem seu início, para além de experiências isoladas ou episódicas, na virada dos anos 1970 para o início da década de 1980², é somente nos anos 1990 que passamos a observar a sua participação mais significativa em alterações e reorganizações estruturais no conjunto da produção musical nacional. A condição independente passa desde então a ser, crescentemente, parte fundamental e decisiva de importantes processos de renovação estética e criativa na música produzida no país - processo que atravessa diversas fases, ciclos e momentos, e se estende até os dias de hoje.

No cenário recente, analisado neste artigo, a possibilidade de se produzir, distribuir, promover, divulgar e viabilizar financeiramente os trabalhos musicais, de forma autônoma às grandes gravadoras, se expande de tal forma que, muitas vezes, vemos borradas as próprias fronteiras e diferenciações conceituais estritas entre "independente" e "mainstream". Artistas como Criolo, Emicida, Tulipa Ruiz, Marcelo Jeneci, Céu ${ }^{3}$, entre outros, são exemplares do que se refere à possibilidade de se alcançar níveis importantes de visibilidade e circulação em veículos de grande mídia e no sistema mainstream, bem como parcerias com grandes marcas e empresas, sem deixar de atuar sob certo modus operandi independente. A despeito de alcançarem públicos mais numerosos e circularem por espaços da grande indústria cultural, estes artistas mantêm sob seu controle a gestão geral de suas carreiras e das articulações e inserção no mercado de suas obras, produtos e shows. Por outro lado, o fato de que artistas consagrados e com trabalhos historicamente associados às majors - como, por exemplo, Chico Buarque, Maria Bethânia, Caetano Veloso, Djavan e Nando Reis tenham produzido e lançado vários discos com estrutura própria, autônoma nos úl-

\footnotetext{
${ }_{1}$ Para uma apreciação histórico-cultural dos múltiplos sentidos, nuances e aspectos relacionados ao termo "independente" no âmbito da produção musical, especialmente no caso brasileiro, incluindo seus rearranjos recentes, conferir Galletta (2014). Aponto aqui, neste início, e durante a maior parte do artigo, para o sentido mais abrangente e genérico desta expressão, voltado à designação das experiências de produção e/ou distribuição musical que se desenvolvem com diferentes níveis de autonomia em relação à estrutura tradicional de produção das majors - grandes gravadoras hoje associadas a três grandes conglomerados transnacionais (Universal Music, Warner e Sony), que controlam a maior parte da comercialização fonográfica mundial.

2 Para mais detalhes sobre este marco temporal, conferir, por exemplo, Vaz (1988), Fernandes de Oliveira (2002), Muller (2005) e Galletta (2014).

${ }^{3}$ Como veremos, não à toa, todos radicados em São Paulo-SP.

GALLETTA, T. Cena musical paulistana dos anos 2010 e o "novo artista da música" na produção independente brasileira pós-internet. Música Popular em Revista, Campinas, ano 5, v. 2, p. 116-141, jan.-
} jul. 2018. 
timos anos, é algo que contribui para tornar mais complexa esta distinção. Em 2013, o produtor musical e jornalista Marcus Preto citava estes últimos artistas (e seus discos lançados sem suporte de grandes gravadoras) para aventar a possibilidade de que o termo "independente" estivesse se tornando uma nomenclatura "datada" (MORAIS, 2013).

Micael Herschmann (2010) aborda uma série de complicadores para a continuidade do uso de uma dicotomia estanque "indie" / "mainstream" no panorama recente, reconhecendo, no entanto, ao final de sua consideração sobre o tema, a relativa pertinência de se permanecer, de alguma forma, trabalhando com estas noções nos estudos sobre música, na medida em que tais distinções continuam a serem vistas como válidas e úteis pelos próprios sujeitos e agentes do campo musical.

Realmente, é possível identificar este uso com razoável frequência nos discursos de artistas, jornalistas e produtores, ainda hoje, em 2018. Por outro lado, cabe ressaltar ainda a existência de um conjunto cada vez mais importante de artistas e bandas desenvolvendo carreiras sólidas sem suporte de grandes gravadoras e sem nem mesmo transitar assiduamente (ou muitas vezes nem transitar) pelos ambientes mais tradicionalmente ligados ao mainstream e à grande indústria. Entre pelo menos várias dezenas de outros casos, são exemplos destes artistas e grupos na música brasileira recente: Kiko Dinucci, Cidadão Instigado, Rodrigo Campos, Liniker, Karina Buhr, Curumin, Bixiga 70, Juçara Marçal, Thiago França, O Terno, Thiago Pethit, Anelis Assumpção, Metá Metá, Rafael Castro, Larissa Luz, Maglore, Romulo Fróes, Instituto, Luiza Lian, Lucas Santtana, Xênia França, Baiana System, Baco Exu do Blues, As Bahias e a Cozinha Mineira, Letícia Novaes, Macaco Bong, Felipe Cordeiro, Wado, Rael, Luedji Luna, Apanhador Só, entre outros ${ }^{4}$. Recebendo recentemente o prestigiado Prêmio Bravo! de Melhor Disco Brasileiro de 2017, o músico, compositor e rapper paulistano Rincon Sapiência fez enfática referência à condição de produção "independente" do seu trabalho:

\footnotetext{
${ }^{4}$ Boa parte desses artistas está radicada na cidade de São Paulo-SP - cidade que, como veremos, abriga um conjunto importante de artistas (incluindo vários outros não citados aqui) com trabalhos de reconhecida relevância na música brasileira atual. A preferência foi por destacar nomes que surgiram em momento mais recente, mas diversos artistas e bandas de outras gerações, como Nação Zumbi, RZO, BNegão, Black Alien, Edgar Scandurra, entre vários outros, têm trabalhado de forma independente, com relevância na cena atual e muitas vezes em parceria com artistas mais novos.

GALLETTA, T. Cena musical paulistana dos anos 2010 e o "novo artista da música" na produção independente brasileira pós-internet. Música Popular em Revista, Campinas, ano 5, v. 2, p. 116-141, jan.jul. 2018
} 
Eu quero agradecer muito a todos os envolvidos neste disco, que foi um trabalho que eu comecei fazendo música na minha casa, no meu quarto, e isso veio a se tornar uma realidade ao passar de alguns anos. E isso foi incrível porque eu sou aquele artista que passou dos 30 anos e estou lançando o primeiro disco. E esse disco eu gravei na minha casa, no meu quarto (...) e isso foi muito importante porque.. o lugar onde eu quero chegar aqui é que.. a música da periferia é assim: nos é negada a educação, nos é negado os instrumentos musicais, nos é negado uma série de coisas e mesmo com todo esse tipo de adversidade a gente está conseguindo fomentar - não só eu com o meu trabalho, mas vários artistas independentes, fazendo música, e usando os recursos que tem, que passam pela tecnologia, por um armário que vira um aquário pra gravação e coisas do tipo. Então eu conheço muitos artistas que estão conseguindo fazer o seu trabalho circular, mas a gente tem feito isso com muita adversidade, com muita dificuldade. E mesmo assim tem acontecido. Então eu quero dividir esse Prêmio com toda a música independente, com toda a música preta, com toda a música de periferia, Eu aproveito esse prêmio pra dividir isso com 'geral' que faz parte dessa corrente, que tem feito coisas alternativas, saindo dos extremos, e fazendo as coisas acontecerem também (Fala de Rincon Sapiência na cerimônia do Prêmio Bravo! de Cultura 2018 realizada em 27 de março de 2018. Ver: REVISTA, 2018) ${ }^{5}$.

Em um momento anterior em sua fala, no mesmo evento, Rincon havia destacado produtores e parceiros que foram vitais para a viabilização do projeto e do disco, enquanto obra e junto ao público. No contexto recente, realmente se tem esvaído, de forma cada vez mais clara, a noção de "independência" como "caminho no qual se faz as coisas sozinho" ou "por si mesmo", abrindo passagem para a ênfase na ideia de parcerias. Entre estas, observamos as mais diversas; desde a estabelecida com amigos, colaboradores e/ou parceiros profissionais autônomos (músicos, produtores, jornalistas, assessores de imprensa, artistas plásticos, videomakers, etc.), até a parceria com empresas, marcas ou mesmo pequenas e médias gravadoras ou selos. Tais relações são vistas frequentemente como "relações de colaboração mútua". O surgimento, por exemplo, de novas iniciativas fonográficas ou de projetos de atuação próxima às cenas independentes na última década, levadas a cabo por grandes empresas, não vinculadas originalmente ao mercado musical - como Natura, Vivo, Oi e Red Bull -, tem papel importante num cenário em que emergem outras formas de

\footnotetext{
${ }^{5}$ Ainda que não seja objetivo deste artigo aprofundar este ponto, vale ressaltar que o trecho citado evoca também, sem dúvida, a questão tantas vezes retomada nos debates sobre "produção independente" e "música independente" (ARTE EM REVISTA, 1984; VAZ, 1988; MULLER, 2005; GALLETTA, 2014): afinal, o fenômeno "independente" designaria tão somente um modo de produção ou apontaria também, em alguma medida, para um conjunto de formulações musicais partilhantes de um leitmotiv comum, no campo das relações entre estética, política e cultura? Para uma discussão mais detida sobre a questão, e seus desdobramentos no contexto brasileiro recente, conferir GALLETTA (2014).

GALLETTA, T. Cena musical paulistana dos anos 2010 e o "novo artista da música" na produção independente brasileira pós-internet. Música Popular em Revista, Campinas, ano 5, v. 2, p. 116-141, jan.jul. 2018.
} 
relação artistas-gravadoras-empresas. Aqui se observa, muitas vezes, vínculos de trabalho nos quais, por exemplo, os direitos autorais permanecem completamente sob controle dos artistas, e em que se verificam relações menos verticalizadas, em termos de poder e atribuições, se comparadas com outros períodos (cf. GALLETTA, 2016). No caso da Natura Musical são selecionados a cada ano, através de editais, artistas e discos que terão suporte da empresa, por meio de leis de incentivo à cultura. Como aponta o músico e pesquisador Cacá Machado, trata-se de um ambiente novo

que se coloca como um desafio ao nosso entendimento ainda preso, como não poderia deixar de ser, em categorias analíticas do mundo analógico. Isto é, certa noção dualista que, por exemplo, opunha as grandes gravadoras aos independentes é obrigada a conviver com a multiplicidade de novos arranjos criativos e produtivos que se expandem vertiginosamente, hoje em dia, em torno de relações mais horizontais e intrincadas (MACHADO, 2016).

Em meio a este cenário de crescente complexidade, este artigo busca refletir, inicialmente, sobre o percurso que nos levou até aqui, analisando o processo de conformação - a partir do impacto decisivo das tecnologias digitais - de um novo lugar para o "independente" na cadeia de produção e consumo fonográficos e na economia da música. Busco também situar a proeminência adquirida pela cena musical paulistana, enquanto polo produtivo e criativo, no novo ambiente pós-internet e redes sociais online, bem como em face da cena independente brasileira mais ampla. Esta cena se apresenta como um lócus especialmente rico para a observação da emergência de novos papéis, atribuições e lugares ocupados pelo artista independente brasileiro nos últimos anos. Neste ponto, abordarei, de forma mais detida, a assunção - por parte, sobretudo, dos músicos independentes - dos papéis simultâneos de “criadores artísticos" e de "gestores", "empresários" e “comunicadores" de suas carreiras, bem como algumas das ambivalências e tensões implicadas neste processo. Os novos potenciais criativos e produtivos que se descortinam no novo cenário necessitam conviver com novas espécies de precariedade, "dependências" e dificuldades que se apresentam ao músico independente e seu trabalho no contexto contemporâneo. Importará considerar, ademais, a riqueza da contribuição à cena musical brasileira por parte desta produção recente - ensejada em meio às novidades tecnológicas 
e às condições específicas do contexto paulistano - sem, no entanto, deixar de chamar atenção para a permanência de uma significativa desigualdade de condições para o desenvolvimento de trabalhos autorais independentes, quando se compara o ambiente da cidade de São Paulo com o restante do Brasil.

\section{Primeira fase de fortalecimento do independente: 0 impacto das tecnologias digitais sobre a produção musical}

Nos anos 1990, foi possível assistir ao aumento progressivo do número de bandas e artistas que passavam a gravar seus próprios Compact Discs (CDs) e demotapes, de forma autônoma ou com o apoio de pequenos selos. Atentas a este movimento, as grandes gravadoras passaram, naquele momento, a prospectar novos artistas naquele campo, de modo cada vez mais intensivo. Estas empresas desenvolviam, então, diversos tipos de parcerias com os "selos independentes", ou passavam a criar, elas mesmas, pequenos selos com aparência de "independentes", com operação fora de sua estrutura tradicional de produção. Ampliava-se, assim, crescentemente, na época, o processo de complementaridade e associação entre os universos "independente" e "mainstream" na música brasileira (cf. DIAS, 2000) . De um lado, esse processo correspondia ao interesse da indústria da música em privilegiar, cada vez mais, as esferas de comercialização e distribuição dos fonogramas, em detrimento do investimento em inovação e experimentação de novas linguagens, gêneros e artistas junto ao seu público. De outro lado, isso se relacionava a uma tendência ascendente de exploração de mercados segmentados (cf. MORELLI, 2008).

A proliferação de "bandas de garagem" neste período, boa parte delas passando a almejar, com o decorrer do tempo, uma maior profissionalização e a assinatura futura de um contrato com as majors, teve como suporte importante, num primeiro momento, o advento das novas tecnologias digitais de produção musical

\footnotetext{
${ }^{6}$ São expressivos deste momento os lançamentos pelo selo Chaos, subsidiário da Sony Music, de discos das bandas Planet Hemp e Chico Science e Nação Zumbi, entre outras, que marcaram a revitalização e renovação do rock nos anos 1990 no Brasil. Cf. <https://oglobo.globo.com/cultura/rock-dos-anos-1990-ainda-marca-presenca-no-cenario-nacional4949058>. Acesso em: 02 mar. 2018.
} 
(cf. VICENTE, 1996). Estas tecnologias reduziram significativamente o custo dos equipamentos necessários à produção fonográfica, resultando tanto no crescimento do número de pequenos e médios estúdios de gravação, como na possibilidade, cada vez mais acessível, da montagem de estúdios caseiros (o disco literalmente "feito em casa").

De toda forma, paralelamente ao aumento da quantidade e qualidade técnica dos discos gravados à margem da estrutura das majors, a esfera da distribuição musical ainda se apresentava como um "gargalo" importante para a circulação mais abrangente dessas produções. Para buscar superar esta limitação, as bandas, artistas e selos independentes contavam então, num período inicial desse processo, principalmente com a produção em série de demo-tapes ou fitas-demo (discos gravados, frequentemente de forma artesanal, em fitas-cassete), bem como com o suporte de circuitos independentes ou underground de shows. Tais circuitos caracterizavam-se por uma significativa precariedade estrutural e financeira, encontrando-se, em boa medida, dependentes do intercâmbio e parcerias das próprias bandas e grupos para se viabilizar. Além disso, como nos indicou em entrevista concedida o músico e produtor Daniel Ganjaman, essas movimentações se mantinham geralmente restritas a nichos muito específicos, com destaque para os segmentos do rock, punk e rap diferentemente daquilo que acontece na cena independente atual, marcada por grande multiplicidade de estilos, gêneros e linguagens.

O surgimento dos primeiros "festivais de música independente" (Junta Tribo, 1993; Abril Pro Rock, 1993; Goiânia Noise, 19957; entre outros), com apoio de emissoras como MTV e parcerias com grandes gravadoras, passam a consolidar novos circuitos marcados por profissionalização crescente, sedimentando mercados emergentes cada vez mais importantes para a música nacional ${ }^{8}$ (cf. HERSCHMANN, 2010). Simultaneamente, a ampliação do acesso pelas bandas e pequenos selos a tecnologias que permitiam a cópia e duplicação de unidades de CD marcam um segun-

\footnotetext{
${ }^{7}$ Anos da primeira edição dos festivais citados.

${ }^{8}$ Neste momento, as movimentações independentes se mantinham ainda, de forma geral, em torno do rock e do rap, mas a emergência de grupos que apresentavam fusões desses gêneros com ritmos e linguagens tradicionais da cultura popular brasileira, como Chico Science e Nação Zumbi e Raimundos, já começava a ampliar, ainda que de forma incipiente, o universo de referências da cena independente nacional. Posteriormente, no contexto digital, essas referências se multiplicarão de forma exponencial e acelerada.
}

GALLETTA, T. Cena musical paulistana dos anos 2010 e o "novo artista da música" na produção independente brasileira pós-internet. Música Popular em Revista, Campinas, ano 5, v. 2, p. 116-141, jan.jul. 2018. 
do influxo de expansão do fenômeno independente naquela década, impactado pelo avanço tecnológico. Se isso representava um grande avanço na superação das barreiras pertinentes à esfera da distribuição, havia ainda condições bastante restritivas para a divulgação e promoção das bandas e obras lançadas junto a públicos mais significativos. Neste sentido, era praticamente imperativa a busca por se assinar contrato com grandes gravadoras, sendo os circuitos e a prática fonográfica independente um degrau muitas vezes necessário para se alcançar isto. Uma vez atingido o objetivo, cessava o período de lida com a "dura batalha" e a fase de incertezas e gestação do trabalho no ambiente independente. Na medida em que passavam a integrar o cast de uma gravadora, as obras e as carreiras destes artistas se integravam às operações, contratos e sistemas de pagamento destas empresas junto às grandes rádios e TVs (o famigerado "jabaculê", ou "jabá"), algo decisivo para o acesso ao público localizado além dos nichos underground.

\section{"Independente 2.0": novas condições de produção, distribuição, formação de público e um novo lugar no conjunto do mercado musical}

Os desenvolvimentos sociotécnicos progressivos em torno da internet a partir do final dos anos 1990 e, sobretudo, ao longo dos anos 2000 (se intensificando ainda mais na atual década) irão tecer, ano a ano, de forma acelerada, um panorama bastante novo no que se refere às condições de distribuição, promoção e divulgação musical, e de articulação produtiva entre atores do campo musical. Os anos 2000 se apresentam, assim, como uma década de transição no processo de composição das condições que possibilitam o surgimento de um novo lugar ocupado pelo artista independente (e crescentemente pelo artista da música, de forma geral), bem como pelo próprio fenômeno independente, no conjunto da cadeia de produção musical. A seguinte fala de Kiko Dinucci - músico e compositor de atuação destacada na cena paulistana e na música brasileira atual junto aos grupos Metá Metá e Passo Torto - é ilustrativa de uma nova condição de possibilidade alcançada progressivamente pelo 
artista da música ao longo dos anos 2000, principalmente a partir dos últimos anos dessa década. Dinucci lançou seus dois primeiros álbuns em 2008 (Pastiche Nagô e Padê).

Hoje não é nenhum bicho de sete cabeças você ser independente. Você meio que já nasce conformado. Você nunca vai bater na porta duma gravadora. Eu nunca conversei com ninguém de gravadora. Eu tenho seis discos, todos Às próprias custas $S / A^{9}$ (Depoimento do músico Kiko Dinucci, gravado pelo autor em debate no SESC Santana, em 22 de março de 2012).

Os projetos musicais de Dinucci têm tido presença assídua, desde então, nas listas de "melhores discos do ano" das principais publicações nacionais especializadas em música, conquistando ainda prêmios de relevo na música brasileira - como, por exemplo, o Prêmio da Música Brasileira e o Prêmio Multishow. Sua trajetória e a fala citada apontam, assim, para elementos importantes no que concerne à condição do artista independente atual, que passa a não somente sobreviver sob este modus operandi de forma continuada, mas também a poder desenvolver por anos a fio um trabalho de relevância destacada no cenário cultural brasileiro, sem precisar assinar contrato com uma grande gravadora ou mesmo com qualquer gravadora (cf. GPOPAI-USP, 2010). A respeito disso, a cantora e compositora baiana radicada em São Paulo, Márcia Castro, nos acrescenta elementos elucidativos:

Tem algo muito positivo neste momento. Antigamente havia a força das gravadoras, mas o funil era muito estreito, poucos artistas alcançavam grande sucesso. Quem não estava inserido nesse sistema não era nada! Hoje você tem uma geração de músicos que talvez nunca experimente aquele êxito de outrora... Entretanto, há neste momento outro patamar onde os artistas independentes se colocam frente ao mercado, o que os possibilita viver de um modo modesto, mas (...) dando continuidade às suas carreiras. Abriu-se uma nova possibilidade. As coisas não são mais estanques: 'Ou você está no mainstream ou você não existe'. Há este novo patamar, em que o principal objetivo não é tornar-se uma celebridade ou ícone de cultura de massa. Esta geração está em outra busca (...). Hoje nós estamos fazendo este projeto [Tabuleiro $\mathrm{BA}^{10}$ ]. Se estivéssemos na década de 1980, ou estávamos ao lado dos grandes nomes da MPB ou não éramos ninguém. Estaríamos tocando em algum barzinho. $\mathrm{O}$ momento em que estamos vivendo é muito peculiar

\footnotetext{
${ }_{9}$ Referência ao disco Às próprias custas S/A, lançado de forma independente, em 1983, por Itamar Assumpção.

10 Evento no qual a cantora estava se apresentando no Rio de Janeiro/RJ no dia da entrevista (29/06/2011), dedicado a promover artistas oriundos da Bahia, como ela, Marcela Bellas e Lucas Santtana - os dois últimos também, à época, com inserção importante na cena paulistana independente. O evento, realizado a cada mês, estava sendo promovido pelo Centro Cultural Banco do Brasil e contava com patrocínio do Ministério da Cultura.
}

GALLETTA, T. Cena musical paulistana dos anos 2010 e o "novo artista da música" na produção independente brasileira pós-internet. Música Popular em Revista, Campinas, ano 5, v. 2, p. 116-141, jan.jul. 2018. 
(Entrevista concedida por Márcia Castro ao blog Banda Desenhada, publicada em 11 de julho de 2011. Ver: DESAFINANDO, 2011).

A cantora paulistana Juçara Marçal, também integrante do grupo Metá Metá com Kiko Dinucci e Thiago França, aponta, a seguir, em direção similar à fala de Castro, para a emergência de novas metas e ideais de "sucesso" no meio independente. Para um conjunto importante de artistas emergentes, a prioridade passa a estar direcionada à construção de espaços profissionais mais propícios e favoráveis à liberdade criativa - ainda que tendo como suporte formas de sustentabilidade mais modestas - que permitam a estes músicos vislumbrar contribuições artísticas, para além das demandas imediatas dos mercados mais voltados para o entretenimento e públicos numerosos. Juçara traça um paralelo de distinção entre o momento atual e o da chamada Vanguarda Paulista dos anos 1980:

Tanto o Itamar quanto o Arrigo [Barnabé] viveram numa época em que, de certa forma, se almejava um status que só as grandes gravadoras poderiam conceder. A geração de hoje não está mais preocupada com isso. Nós finalmente não precisamos mais dar certo. Não precisamos ser celebridades. Isto determina muito a forma como lidamos com o nosso trabalho, sem toda a preocupação que era natural daquela época. Não temos aquela angústia em lidar com a impossibilidade de chegar a um patamar que o Itamar almejava e que, de direito, era dele (Entrevista concedida por Juçara Marçal ao blog banda Desenhada, publicada em 29 de setembro de 2011. Ver: Z DA QUESTÃO, 2011).

A condição independente passa então a não ser mais um "lugar de passagem", mero "trampolim" ou "vitrine" transitória. Com a expansão da importância de mercados segmentados e de nicho - que se intensifica a partir da aproximação de pessoas e grupos com afinidades e interesses comuns no ambiente digital em rede (ANDERSON, 2006) - se incrementa não só as condições financeiras de produção continuada no meio independente, mas as possibilidades de alcance de projeção, status e reconhecimento artístico em nível nacional, atuando-se exclusivamente sob este modus operandi. Por outro lado, nota-se que, neste cenário sociotécnico, os músicos independentes têm encontrado em públicos menores seus "pares culturais", desfrutando, assim, deste sentimento de identificação e de conseguir falar com as pessoas relevantes para seus próprios universos. Em outras palavras, há aí uma satisfação que advém da construção de circuitos de produção-fruição artístico-cultural, capazes 
de fazer existir mundos e realidades socioculturais simbolicamente importantes para eles ${ }^{11}$. Claro que "nem tudo são flores" e cumpre perceber que - como veremos de forma mais detalhada a seguir - esta nova condição aqui enfocada se concretiza com mais força especialmente no contexto econômico, cultural e geográfico bastante específico de São Paulo. Para um número significativo de artistas independentes de tamanho médio, mesmo nesta cidade a lida da produção independente ainda permanece sujeita a diversas instabilidades, incertezas e dificuldades, sendo marcada, não raramente, por uma batalha mês a mês em busca de uma sustentabilidade financeira mais estável. Ainda que em meio a estas restrições, e limites significativos quanto à sua descentralização geográfica, trata-se aqui, de toda forma, de um conjunto de possibilidades bastante novo no contexto da produção musical brasileira, que tem gerado importantes frutos produtivos e criativos.

Tendo como referência sua experiência ligada ao cenário paulistano, Kiko Dinucci afirma: “nos anos 1990 não era possível viver de música no meio independente. Nos anos 2000 não era. 2005 pra trás não era. Todo mundo tinha emprego, todo mundo se 'fodia'” (Entrevista concedida ao autor por Kiko Dinucci em 05 de abril de 2012). Dinucci faz parte de uma geração e de um conjunto amplo de artistas que, iniciando seus trabalhos na música nos anos 2000 (alguns até mesmo na segunda metade dos anos 1990), atingem o ponto inicial de culminância de suas carreiras na virada dos anos 2000 para os 2010. Neste momento, passa a ser possível reconhecer com mais clareza, através da cobertura de mídia especializada, do próprio relato dos artistas e da profusão de obras a obter reconhecimento em circuitos segmentados de âmbito nacional, a existência de um "novo momento na música brasileira", bastante impactado pelo cenário digital ascendente. Ao mesmo tempo, era possível constatar a emergência de uma nova vitalidade e efervescência na cena musical da cidade de São Paulo, que se alimentava do novo momento da música nacional e ao mesmo tempo se colocava como um de seus principais polos aglutinadores e criativos (cf. GALLETTA, 2016). .

\footnotetext{
11 Algo que mais recentemente vem sendo eventualmente problematizado em alguns posicionamentos de artistas da cena, tendo em vista as "bolhas de realidade" produzidas por algoritmos de redes sociais como Facebook, Instagram e outras (ROUVROY e BERNS, 2015).

GALLETTA, T. Cena musical paulistana dos anos 2010 e o "novo artista da música" na produção independente brasileira pós-internet. Música Popular em Revista, Campinas, ano 5, v. 2, p. 116-141, jan.jul. 2018.
} 
O impacto da popularização de uma internet com processamento de conexão cada vez mais rápido e do desenvolvimento de redes sociais online como Orkut, Trama Virtual e MySpace, a partir de meados dos anos 2000, assume um papel decisivo na conformação deste novo cenário. Tal cenário irá se consolidar de forma cada vez mais plena a partir da virada desta década para os anos 2010 - momento marcado pela popularização exponencial de novas redes sociais como o Facebook, Twitter, Instagram, bem como dos smartphones e da internet móvel.

Desde o final dos anos 1990, observa-se a constituição progressiva de uma “internet para a música” (GALLETTA, 2016), em que, num primeiro momento, ampliam-se as possibilidades dos circuitos informativos e de redes de comunicação e conexão entre artistas, produtores, em torno da música (através de sites, blogs, emails, softwares de troca de mensagens), especialmente daquela feita e fruída para além do mainstream. Num segundo momento, já nos anos 2000, disseminam-se o MP3 e os softwares de compartilhamento de arquivos musicais peer-to-peer (P2P), popularizando-se progressivamente a "cultura do download" - algo que marca especialmente a geração de artistas brasileiros aqui enfocados, assim como o seu futuro público. O acesso potencial ao conjunto da produção musical brasileira e mundial do passado e do presente, por meio da rede mundial de computadores, se torna um fator importante de substancial ampliação de referências que irá marcar, sobremaneira, esse "novo momento da música brasileira" e a "cena paulistana" (idem). No entanto, até meados dos anos 2000 as novidades técnicas ainda não favoreciam o encontro dos artistas independentes (e suas produções musicais) com “seus públicos” potenciais. A arquitetura em rede das chamadas redes sociais terá um papel decisivo neste aspecto, conectando grupos de afinidade e associando em plataformas comuns as possibilidades de promoção, divulgação e distribuição dos trabalhos musicais.

A estes fatores associados à tecnologia se somam outros, como, por exemplo, a implementação de novas políticas de incentivo à cultura e de financiamento de projetos e circuitos por meio de leis e editais em nível federal, marcadamente a partir das gestões dos ex-ministros da cultura Gilberto Gil (2003-2008) e Juca Ferreira (2008-2010) (cf. MANEVY, 2010). Em parte, a partir de iniciativas e articulações criativas do próprio campo musical, mas contando em boa medida com este 
ambiente tecnológico, cultural, político e econômico mais favorável, ampliam-se significativamente, entre meados dos anos 2000 e início dos anos 2010, a quantidade de festivais independentes de música no Brasil, bem como o número de projetos de natureza variada voltados para o circuito de shows em torno da produção independen$\mathrm{te}^{12}$.

\section{"Existe música em SP"13: a cena paulistana como polo criativo e produtivo proeminente da música brasileira recente}

Todos estes processos de fortalecimento das cenas independentes no Brasil correm em paralelo com a acentuada e progressiva crise da indústria fonográfica tradicional - intimamente associada ao declínio da centralidade da comercialização do "disco físico" na economia da música. Pressionada pelas dificuldades impostas pelo cenário técnico e econômico emergente, as grandes gravadoras passam a privilegiar, de modo ainda mais intensivo no período, o investimento em artistas e gêneros de sucesso mais imediato ou garantido, com produção planejada e voltada para públicos numerosos (cf. MIDANI, 2008; PINHEIRO e PAIVA, 2010). Como sublinha o produtor paulistano Maurício Tagliari, isso fez com que se deslocasse gradualmente do Rio de Janeiro (onde se localizavam as principais gravadoras e um conjunto importante de veículos do mainstream) para São Paulo o polo central de atração, no território nacional, de artistas e bandas com trabalhos autorais e interessados na inovação e experimentação de linguagens; ou ainda, ligados a gêneros pouco priorizados pela indústria.

De fato, o novo cenário tecnológico, econômico e fonográfico emergente na música nacional no período recente encontra na cidade São Paulo uma série de

\footnotetext{
12 Fundada em 2005 com 14 festivais associados, a Abrafin (Associação Brasileira de Festivais Independentes) sofre uma cisão em 2011, dando origem, em 2012, à Rede Brasil de Festivais (RBF). Neste último ano, já eram 107 festivais associados à RBF. No mesmo período, a entidade dissidente Festivais Brasileiros Associados, na qual se agruparam festivais antigos como o Abril pro Rock (PE), Goiana Noise (GO), MADA (RN), entre outros, contava com 17 festivais (cf. GALLETTA, 2016).

${ }^{13}$ Referência à música "Não existe amor em SP" que, lançada como single em 2011, apresentou o cantor e compositor Criolo a um público mais amplo em nível nacional, para além do segmento rap, representando um momento icônico em relação ao fortalecimento da música de São Paulo na virada dos anos 2000 para os 2010.
}

GALLETTA, T. Cena musical paulistana dos anos 2010 e o "novo artista da música" na produção independente brasileira pós-internet. Música Popular em Revista, Campinas, ano 5, v. 2, p. 116-141, jan.jul. 2018. 
características particulares, que irão proporcionar um terreno fértil para a consolidação de um importante polo criativo e de inovação musical independente neste lugar. É claro que um dos fatores fundamentais neste processo se refere à condição econômica privilegiada da cidade, e do estado de São Paulo de um modo mais geral, se os comparamos com outros centros. Esta condição tem, ainda, implicações importantes no que se refere a outros fatores, como a existência de uma rede substancial de equipamentos e recursos dedicados à cultura na cidade, com destaque especial para a rede SESC-SP. Também é relevante a presença de um conjunto significativo de veículos de mídia na cidade, com cobertura especializada em música ${ }^{14}$ - talvez mais voltada para mercados segmentados do que os canais de imprensa do Rio de Janeiro, por exemplo. É possível ressaltar ainda, especialmente: a) o significativo circuito de casas noturnas e espaços de shows direcionados a públicos interessados nas propostas autorais de artistas independentes; b) a concentração em uma região territorial específica na cidade (que, em cerca de quatro quilômetros de raio, abrange bairros como Lapa, Pompéia, Vila Madalena, Pinheiros e o quadrilátero Baixo Augusta), de bares, casas noturnas, estúdios, gravadoras, residências de artistas, jornalistas, produtores culturais, e de um público potencial para os shows citados (formado especialmente por universitários, artistas e agentes ligados à produção cultural) - algo que aponta para oportunidades de encontro, contato, convivência e estabelecimentos de parcerias entre os atores da cena. Estes fatores, somados a diversas especificidades das associações entre a cultura digital emergente e a cultura urbana paulistana (com sua "cultura noturna" e redes culturais peculiares, que formariam um público potencialmente mais receptivo a trabalhos independentes autorais), irão favorecer articulações empreendidas por artistas e outros agentes da cena na direção da construção de um amplo circuito de parcerias, interconexões e produção colaborativa, capaz de viabilizar, fortalecer e projetar os trabalhos desenvolvidos (cf. GALLETTA, 2016).

Por outro lado, a cena de São Paulo se beneficia de um momento de nova vitalidade produtiva e criativa para a produção musical brasileira como um todo, a

\footnotetext{
14 Por exemplo, jornais como Folha de S. Paulo e Estado de São Paulo, revista Rolling Stone Brasil, programas na TV Cultura especializados em música, e certo conjunto de programas de rádio em FM e online. Também tem destaque neste quesito um sem-número de blogs e sites especializados em música brasileira, com produtores radicados na cidade. Para mais detalhes, conferir Galletta (2016).

GALLETTA, T. Cena musical paulistana dos anos 2010 e o "novo artista da música" na produção independente brasileira pós-internet. Música Popular em Revista, Campinas, ano 5, v. 2, p. 116-141, jan.jul. 2018.
} 
partir da virada dos anos 2000 para os anos 2010. Gravar e divulgar discos se tornou cada vez mais fácil, ao mesmo tempo em que as redes sociais online passaram a conectar, progressivamente, produtores, artistas, comunicadores digitais, entre si e entre os seus públicos segmentados ou de nicho. Esse processo se estende pelos mais variados contextos geográficos e culturais, se manifestando de distintas formas e com desiguais possibilidades de desenvolvimento econômico das cenas musicais, suas produções e artistas, em cada localidade. Comentando, em 2011, sobre a emergência de um novo momento na música brasileira, bastante relacionado com o impacto das tecnologias digitais nas condições de produção e distribuição musical, o cantor e compositor Romulo Fróes se manifestava da seguinte forma a respeito do tema:

Tem essa coisa da música brasileira independente só estar sendo possível ser desenvolvida em São Paulo - eu digo economicamente. Isso de se criar, o Brasil inteiro está conseguindo, mas de se formatar e de virar economicamente viável, só São Paulo está permitindo isso. Isso por um lado é triste; por outro lado, eu que estou em São Paulo travo contato com gente do Ceará, de Salvador, de Pernambuco (especialmente, há muitos anos já). E aí isso acaba trazendo uma coisa que eu acho que foi muito rica pra essa nova música brasileira, que é você estar convivendo com gente de lugares diferentes, realidades diferentes (Entrevista concedida pelo cantor e compositor Romulo Fróes ao programa Alexandra Makowski, publicada em 15 de junho de 2011. Ver: MAKOWSKI, 2011).

\section{"Cena paulistana brasileira"?: a importância dos músicos migrantes e da nova cena independente brasileira para a cena de São Paulo}

Na medida em que a capital paulistana se conformava, ao longo da segunda metade dos anos 2000 e início dos 2010, como um epicentro criativo importante no cenário brasileiro, cada vez mais artistas migrantes de outros estados e regiões do país se juntavam aos músicos que ali já estavam. Quanto mais forte a cena se tornava, no período, mais atraía novos artistas de outras localidades. Quanto mais migrantes com bons trabalhos artísticos - e em busca de um melhor ambiente econômico, logístico e de divulgação para suas obras - esta cena recebia mais se enriquecia musical e culturalmente, integrando a si recursos humanos, artísticos e criativos oriundos de outros territórios do país. Ampliavam-se, então, as condições para que um 
conjunto diversificado de produções fosse gestado em âmbito local e regional até que estes artistas vislumbrassem uma "mudança de casa" para São Paulo - muitas vezes após significativas trajetórias artísticas em seus locais de origem. A contribuição diferenciada, trazida por estes músicos, se soma à peculiaridade da cultura musical paulistana e aos talentos criativos de seus artistas, bem como às vivências urbanas próprias à cidade - processo decisivo para a composição da força musical, atração e singularidade cultural desta cena.

Por outro lado, a despeito das diversas especificidades da cena paulistana (tanto estéticas quanto territoriais, culturais e econômicas), ela se apresenta como um fenômeno que expressa, de modo emblemático, algumas das novidades que se manifestam na música brasileira pós-internet nos últimos anos. Entre estas novidades, se destaca, por exemplo, o tema primeiramente tratado da emergência de um novo lugar para a produção independente na cadeia fonográfica nacional e de um novo lugar da possibilidade independente no processo de construção de carreiras de artistas, especialmente aqueles interessados em maiores níveis de autonomia criativa e na experimentação de novas linguagens e propostas estético-musicais. Por outro lado, é possível identificar na cena paulistana um lócus privilegiado a partir do qual é possível observar os novos papéis emergentes assumidos individual e simultaneamente pelo "artista da música" na cadeia de produção musical atual15.

\section{Potenciais ampliados, desafios e novas espécies de precariedade: o artista "criador-empreendedor" e "multitarefa"}

No panorama impactado pelas novas tecnologias digitais, descrito até aqui, altera-se substancialmente o processo social de mediação entre as dimensões da música "enquanto arte" e "enquanto empreendimento econômico-produtivo"; di-

15 Além das simultaneidades expostas na seção a seguir - pertinentes à justaposição das esferas criativa e de produção cultural, comunicação e gestão de carreira - cabe registrar aqui as justaposições que ocorrem no interior do próprio processo criativo. Ainda que não seja o foco deste artigo desenvolvê-las, é pertinente assinalar aqui a importância no cenário em questão do frequente acúmulo das funções de composição, interpretação, produção e arranjo por um mesmo artista ou grupo - com consequências criativas e estéticas significativas, decorrentes deste contato direto dos músicos com toda a parte de técnica em torno da produção sonora, com suas máquinas, equipamentos de masterização, gravação, etc. Para mais detalhes sobre o tema, conferir Galletta (2016).

GALLETTA, T. Cena musical paulistana dos anos 2010 e o "novo artista da música" na produção independente brasileira pós-internet. Música Popular em Revista, Campinas, ano 5, v. 2, p. 116-141, jan.jul. 2018. 
mensões historicamente constitutivas da atividade musical profissional desenvolvida nas modernas sociedades capitalistas. No período de centralidade da tradicional indústria fonográfica enquanto organizadora da produção musical, esta mediação cabia, mais efetivamente, a estas empresas, e a profissionais como diretores artísticos, de marketing, de produção, empresários de artistas, produtores, assessores de imprensa (cf. MORELLI, 1991; DIAS, 2000). Com a crescente consolidação deste modo de produção, na segunda metade do século $X X$, verificou-se o fenômeno de artistas que puderam dedicar-se mais exclusivamente à criação e à produção musical sem ter que lidar tão diretamente com a preocupação de planejar a inserção econômica de seus trabalhos no mercado.

As diferenças de perspectiva entre os interesses artísticos e criativos dos artistas e as demandas e exigências colocadas pelos profissionais e empresas (estes últimos, os principais atores dedicados a pensar a música enquanto atividade e econômica), engendravam negociações constantes entre as partes. Estas negociações não se davam - especialmente no caso da relação entre artistas e gravadoras - em condições iguais para os dois lados; os conflitos de interesse presentes nestas relações atravessaram e marcaram, em alguma medida, a carreira de boa parte dos artistas durante o período (cf. BAHIANA, 1980; DIAS, 2000; VICENTE, 2002; MIDANI, 2008). Por outro lado, para artistas "marginais" ou músicos iniciantes talentosos que se encontravam excluídos deste sistema produtivo, estas empresas mediadoras eram percebidas muitas vezes como algozes em relação ao tipo de trabalho musical que se propunham a desenvolver.

\footnotetext{
Fazia sentido reclamar nos anos 1990, quando sua única chance era assinar com a porra de uma gravadora e ser feliz por causa disso. Você falava: "porra, não consegui entrar na máquina, então sou um maldito...". Hoje em dia, que você não precisa da máquina, não dá pra você ter o discurso derrotado mais. Não cabe mais, porque você tem o controle de tudo. Você não precisa da Globo mais pra viver; ou assinar com a Warner, com a Universal. Se você tem um trabalho bom e trabalha bastante... (Entrevista concedida ao autor por Kiko Dinucci em 05 de abril de 2012).
}

A ampliação de possibilidades atual convive, como veremos logo adiante, com novas dificuldades e precariedades e tal ambivalência pode ser percebida comumente até mesmo no relato de um mesmo artista, como na declaração anterior de 
Dinucci e nesta outra a seguir. O que parece ser comum na busca de grande parte destes músicos é a superação das diversas espécies de "precariedade" pertinentes ao trabalho artístico, tanto as que se manifestam no contexto independente como as que se interpõem no mainstream:

\begin{abstract}
Pra mim é muito legal você ser independente, é muito bonito, tem o seu lado romântico, mas é precário. É sempre precário. Ninguém é independente porque quer. Sei lá... Por outro lado, eu me assusto com uma coisa de cultura de massa. Eu me assustaria em tocar em programa de TV e sentir vergonha, sabe? Estar tocando e ter dez mulheres mostrando a bunda enquanto eu estou tocando e o apresentador gritando no meio da música. Eu gostaria que a minha música tivesse alcance, mas não dentro dos padrões da cultura de massa, a ponto de você tocar em um lugar e se sentir idiota. Mas também não é uma coisa: 'nossa, eu sou underground pra caramba'. Eu acho que o banheiro tem que ser limpo mesmo. Banheiro tem que ser limpo. A casa de show tem que ser agradável pro público que vai; o som tem que ser bom. Não pode confundir underground com coisa precária. Mas é isso. O ideal é ter o mínimo de dignidade pra quem faz arte, desde o cara que toca na rua ao cara que toca no mainstream (Entrevista concedida por Kiko Dinucci ao autor em 05 de abril de 2012).
\end{abstract}

Sendo, cada vez mais, a condição independente uma condição "natural", ou quase inevitável (ao mesmo tempo em que desejável no atual contexto), para o artista em busca de inovação e experimentação de linguagens - ou mesmo para os artistas e bandas iniciantes voltados à linguagem pop e aspirantes a um lugar no mainstream - a condição de artista "criador-empreendedor" e de "artista multitarefa" acaba por ser a condição da maior parte dos artistas da música hoje. Só não faria parte deste conjunto o grupo relativamente seleto dos artistas vinculados às grandes gravadoras, que circulam amplamente pelos circuitos mainstream e que dispõem de assessorias e equipes de razoável tamanho, com divisão de trabalho especializado. Há, ainda, é verdade, uma faixa intermediária, composta por aqueles artistas - citados no início deste artigo - que, emergindo do contexto independente e ainda mantendo este modus operandi de produção, acabam por alcançar uma amplitude de público e reconhecimento que lhes permitem constituir em torno de si equipes razoavelmente estruturadas de trabalho. De todo modo, tanto estes músicos, como até mesmo parte dos artistas ligados às grandes gravadoras, tem acabado por atuar de maneira bastante proativa em esferas externas ao fazer artístico propriamente dito. Tais atividades se distribuem entre, por exemplo, a gestão estratégica de suas carrei- 
ras, produção musical e direção artística das obras, arranjos das composições, construção de imagem junto ao público, administração de perfis em redes sociais, entre outras atividades - um tipo de atuação abrangente a que parecem ser convocados com muito mais força hoje do que acontecia em momentos anteriores da indústria fonográfica.

De qualquer maneira, é possível pensar que o artista da música que mais arquetipicamente e intensamente expressa este novo momento da economia e das dinâmicas socioculturais pertinentes ao ofício musical no contexto pós-digital é, de fato, aquele que atua no universo independente, conjugando com frequência em si mesmo, e no seu cotidiano diário, uma multiplicidade de tarefas e habilidades profissionais que vão muito além da parte artística. Este novo artista da música tem, realmente, que "se virar", para dar conta das diversas e crescentes demandas inerentes à sua condição. Como coloca Márcia Castro:

O músico acumula hoje muito mais funções, não só artísticas, mas também de produção. A gente acaba gerindo a nossa própria carreira. Praticamente não existe mais aquele modelo antigo em que há a figura do empresário que comanda e você fica lá, inerte, sem saber de nada. É muito raro. Hoje em dia, o que acontece é você ter parceiros que te ajudam a desenhar a sua carreira. Até porque ninguém a conhece melhor do que você mesmo. Ninguém entende melhor o seu público do que você. Esse tête-à-tête, esse contato com os fãs... Ver quem está na internet respondendo suas postagens, quem está comentando seus vídeos... Ler e responder e-mails leva um "teeempo"... Lidar com essa parafernália de redes sociais... Isso vira trabalho! $\mathrm{E}$ eu batalho pela minha carreira como um leão! [risos]. (...) A gente faz de tudo para que a música continue acontecendo. O lado ruim é que trabalhamos muito mais... Se você trabalha 10 horas por dia, acaba dedicando umas seis horas para a produção e quatro para a música. Queria ter tempo para poder estudar e ouvir mais coisas, sabe? Acho importante a gente parar e ficar escutando música. Só por escutar, ter contato com outros sons. (...) Isso vai alimentando nosso trabalho também. Mas todo este acúmulo faz parte do nosso tempo e como nós somos a geração de transição, talvez sintamos mais os seus efeitos (Entrevista concedida por Márcia Castro ao blog Banda Desenhada, publicada em 11 de setembro de 2011. Ver: DESAFINANDO, 2011).

Em meio a este trabalho cotidiano intenso e a estas múltiplas e diferentes funções assumidas, descritos por Castro, torna-se, frequentemente, um desafio para o artista encontrar ou separar tempo para se dedicar à variada gama de processos e atividades envolvidas diretamente com o fazer criativo e o musical propriamente dito (como criação, estudo, produção musical, gravação, performances ao vivo). A necessidade de estar "sempre correndo atrás", sobretudo a intensidade que isso al- 
cança muitas vezes em um meio musical no qual observamos uma explosão exponencial da quantidade de produções em busca de visibilidade - nas mídias especializadas, redes sociais online e circuitos de shows -, aponta para a emergência de novos aspectos de precariedade presentes no trabalho do músico contemporâneo (cf. SEGNINI, 2011). No Seminário da Música Brasileira realizado na USP durante o Congresso Fora do Eixo, de 2011, o produtor musical Carlos Miranda - um dos mais importantes no cenário nacional recente - indicava, não sem certo humor, à plateia de músicos independentes que o ouvia que artistas como Emicida e Daniel Ganjaman (que o acompanhavam na mesa naquele momento) estavam desenvolvendo seus trabalhos com aquela amplitude porque, simplesmente, "não dormiam". E, assim, recomendava o mesmo à audiência. Queria reafirmar com isso, exagerando um pouco, o trabalho intenso e diuturno que o artista independente precisa realizar para conseguir dar conta das articulações profissionais todas em torno de seu trabalho (de modo que sejam suficientes para a expansão do seu trabalho na cena) e ainda se dedicar intensamente ao aprimoramento e desenvolvimento de sua técnica musical e de sua arte propriamente dita (aspecto também enfatizado por diversos músicos que entrevistei). Tudo isso está bastante relacionado com um meio musical que, acima de tudo a partir da expansão digital recente, apresenta oportunidades limitadas - e atenção finita dos públicos - para uma quantidade incontável de músicos e bandas gravando e divulgando seus trabalhos na internet, e lançando discos a cada ano. Como comenta o cantor e compositor Pélico,

A questão é como você faz pra sair, como você faz pra ter um pouco mais de visibilidade. Como você faz pra se sobressair em meio a este mar de produção (...).Alguém me disse isso e eu fiquei espantado: no primeiro semestre de 2011, foram lançados quatro mil CDs só na região sudeste. Então, neste sentido, uma coisa que eu acho que ninguém mais acredita hoje no meu meio é que a internet é milagrosa. Que é algo que existia há algum tempo atrás... O ponto é que a quantidade de gente produzindo música que se tem hoje, e batalhando pra divulgar sua música também, é inacreditável! (Entrevista concedida ao autor por Pélico em 30 de abril de 2012).

Diante do declínio da centralidade da comercialização do "disco físico" na economia da música contemporânea - decorrente em grande medida da circulação de arquivos musicais por meio de plataformas digitais - os shows ao vivo assumem uma importância fundamental na sustentabilidade das carreiras de artistas e bandas. 
Mas, para além dessa importância econômica decisiva, estar presente, com certa frequência, nos circuitos de shows pertinentes ao segmento com o qual o artista lida passa a ser essencial para que seu trabalho se faça presente junto ao público, artistas e demais formadores de opinião na cena. As apresentações ao vivo são sempre oportunidades para gerar matérias na cobertura especializada, ou para que um post do artista sobre o evento seja feito em suas redes sociais (e compartilhado por seus parceiros e fãs, aumentando seus seguidores), além de estreitar laços e parcerias com outros músicos através de convites para intercâmbios e participações mútuas em apresentações. Tudo isso favorece o fortalecimento da figura e do trabalho do artista na cena, bem como para a formação e ampliação gradual de seu público:

\footnotetext{
Show é o mais importante para o artista ter uma vida [no meio musical]. Eu acho assim: o artista que não toca, que não existe no mundo do show business, ele, de fato, não existe. Eu tenho alguns projetos aqui [na gravadora independente $Y B$ Music], que eu prefiro não citar os nomes, que são discos lindos, maravilhosos, "fudidos", que o artista não saiu pra fazer nada! Saiu a crítica no jornal positiva, na revista Bravo positiva, na Rolling Stone positiva e acabou! Entendeu? Então, assim, fazer show é fundamental (Entrevista concedida ao autor pelo produtor musical e proprietário da gravadora YB Music, Maurício Tagliari, em 10 de maio de 2012).
}

Até que o trabalho do artista ou da banda adquira certo "tamanho" na cena e no mercado, as articulações prévias necessárias para a geração de boas e frequentes oportunidades de shows exigem não somente grande empenho e esforço continuado por parte destes músicos na venda e produção de suas apresentações e eventos, mas também capacidade de estabelecer alianças e parcerias, dispor de carisma para tecer boas relações, inteligência para pensar estrategicamente suas inserções no segmento musical com o qual dialogam, entre outras qualidades e habilidades. Ao mesmo tempo, são eles próprios que administram suas redes sociais online, suas personas digitais e, mais amplamente, são responsáveis por desempenhar um papel público como "agentes culturais", que participará de modo decisivo na composição de sua obra e trabalho junto ao público. É claro que estas novas exigências são sentidas e vividas de diferentes formas pelos artistas, e até por um mesmo artista a depender do contexto e momento. Percebemos isto nos distintos ângulos sobre o tema enfatizados pelos cantores e compositores Thiago Pethit e Cláudia Dorei: 
Entrevistador: Você deve sofrer uma pressão imensa. Sem empresário, selo ou gravadora, o acúmulo de tarefas deve deixá-lo exaurido...

Thiago Pethit: É um caos. Se por um lado sei que isso pode acabar me matando, por outro, as conquistas são muito gratificantes. Afinal, eu fiz tudo, ninguém meteu o bedelho, ninguém meteu a mão. Tenho 50 mil pessoas na minha fan page no Facebook. Para um artista que trabalha assim, é muita gente. Outros têm o caralho a quatro, gravadora, os melhores empresários do ramo e não chegam a isso (Entrevista concedida por Thiago Pethit ao blog Banda Desenhada, publicada em 07 de fevereiro de 2013. Ver: DA NATUREZA, 2013).

Não basta só você fazer a música, você também tem que ter toda uma estratégia para se promover. (...) E eu não consigo fazer tudo... Não consigo fazer política e música ao mesmo tempo! A gente tem que ser mil e um! Acho que esta é a principal característica da nossa geração. Porque nós corremos atrás, nós divulgamos e produzimos melhor do que muitos produtores executivos que tem por aí. Ninguém pensa tanto na nossa carreira quanto nós mesmos (Entrevista concedida por Cláudia Dorei ao blog da Banda Desenhada, publicada em 28 de outubro de 2011. Ver: DECLARE, 2011).

O fortalecimento da figura do artista que atua e que é observado de forma mais abrangente enquanto "agente cultural" nos é indicado pelos jornalistas Alexandre Matias e Pablo Myazawa, que à época trabalhavam, respectivamente, no jornal $O$ Estado de São Paulo e na revista Rolling Stone Brasil:

Hoje a crítica musical, cada vez mais, sai um pouco do âmbito musical pra analisar o artista de uma forma mais completa, enquanto agente cultural. Tão importante como o disco é o show, a entrevista que ele dá, o comportamento dele em público - seja pessoalmente, num programa de TV, ou nas redes sociais (Fala do Alexandre Matias no $3^{\circ}$ Congresso Internacional de Jornalismo Cultural, em 19 de maio de 2011. Ver: SESC, 2011).

O artista hoje em dia é o vendedor da sua arte, o comerciante do que ele produz, do que ele vende e tem a oferecer e ele vai ser avaliado por tudo isso que ele oferece. E esse artista não vende apenas o disco; às vezes ele vende músicas em separado, ele vende uma performance em um show, ele vende um conceito, ele vende uma ideia, ele vende uma determinada atuação no Facebook, por exemplo (Fala de Pablo Myazawa, no $3^{\circ}$ Congresso Internacional de Jornalismo Cultural, em 19 de maio de 2011. Ver: SESC, 2011).

Há, realmente, um papel importante dos veículos tradicionais de mídia (jornais, revistas, programas de TV especializados em música) no processo de filtragem daquele mar de produções independentes mencionado por Pélico. Aparecer nestes espaços, por si só, não é suficiente, como vimos na fala anterior de Tagliari, mas não deixa de trazer uma importante atribuição de status e prestígio às obras e artistas algo que, associado à repercussão e sólido trabalho do músico ou banda no circuito de shows e nas redes digitais da cena, contribui para que eles se sobressaiam em 
meio a tantos outros. Quando isso acontece de forma simultânea em alguns ou vários veículos de relevo (sem excluir aqui a importância simultânea de blogs e páginas em redes sociais) - com comentários positivos, por exemplo, em torno de um disco ou show - gera-se o "burburinho"; o "buchicho" na cena e no meio jornalístico, tão caro às carreiras artísticas.

Finalmente, vale destacar uma vez mais que a esfera das relações pessoais, das afinidades artísticas e afetivas, das amizades - entre músicos, jornalistas, produtores, etc. - participa de forma bastante importante de todo este cenário descrito até aqui. Como coloca Romulo Fróes:

Mesmo que o cara seja bom, sem amizades não se consegue nada. Não existe o cara que está fazendo sozinho... O cara que está fazendo sozinho não está fazendo. (...) Antigamente era possível a figura do "gênio muito louco" do qual as gravadoras tomavam conta... Têm exemplos disso. Têm vários, aliás. Mas esse cara acabou. Não tem mais espaço pra isso, tem que "trampar", tem que botar a cara na rua, tem que ser amigo (Entrevista concedida ao autor por Romulo Fróes em 04 de outubro de 2012).

É significativo, nesse sentido, o apontamento de Roberta Martinelli, apresentadora do programa "Cultura Livre" (TV Cultura), dedicado à "nova música brasileira independente" . Ao indicar que a principal característica definidora da música independente contemporânea e o seu ponto forte estão relacionados com o fato de o projeto artístico (de um disco ou da carreira de modo geral) ser todo comandado (ou gerido) pelo artista, enfatiza que esta independência é, também, por outro lado, "uma dependência enorme de um coletivo de artistas que 'compra' tua ideia" (apud MORAIS, 2013). Se este ponto se encontra relacionado, de um lado, com a percepção dos próprios artistas sobre o trabalho de seus colegas - percepção que acaba por influenciar a apreciação de jornalistas e veículos de mídia sobre a cena -, ele também se refere ao intercâmbio produtivo e colaborativo entre os artistas (participações mútuas em discos e shows, por exemplo). Este intercâmbio se mostra vital, pois, na maior parte das vezes, é ele que permite driblar as, quase sempre presentes, dificuldades financeiras - hoje ainda inerentes à maior parte do "fazer independente" no contexto nacional. De toda maneira, como salientamos, a "independência" em relação às grandes gravadoras implica sempre, em outros tempos e no tempo atual, perceber e atuar sobre a "(inter)dependência" entre diversos e tantos outros fatores além desse, 
sem dúvida importante, indicado por Martinelli. Para além de qualquer idealização ou "glamour" em torno da "condição independente" no Brasil recente, cabe notar não somente a riqueza da contribuição criativa das produções que têm sido feitas sob este modo de produção, mas também - como insistem tantos artistas e produtores - a urgência de se trabalhar política, econômica e culturalmente para melhorar suas condições.

\section{Referências}

ANDERSON, Chris. A cauda longa: do mercado de massa ao mercado de nicho. São Paulo: Campus, 2006.

ARTE EM REVISTA: São Paulo: CEAC (Centro de Estudos de Arte Contemporânea), ano 6, n. 8, 1984. Edição especial: Independentes.

BAHIANA, Ana Maria. Nada será como antes: MPB nos anos 70. Rio de Janeiro: Civilização Brasileira, 1980.

DA NATUREZA dos lobos. Banda desenhada, 7 fev. 2013. Disponível em: <http:/ / bandadesenhada01.blogspot.com.br/2013/02/da-natureza-dos-lobos.html>. Acesso em: 20 fev. 2018.

DECLARE independência. Banda desenhada, 28 out. 2011. Disponível em: <http:/ / bandadesenhada01.blogspot.com.br/2011/10/declareindependencia.html>. Acesso em: 20 fev 2018.

DESAFINANDO o coro dos contentes. Banda desenhada, 11 jul. 2011. Disponível em: <http:/ / bandadesenhada01.blogspot.com.br/2011/07/desafinando-o-coro-doscontentes.html>. Acesso em: 20 fev. 2018.

DIAS, Márcia Tosta. Os donos da voz: indústria fonográfica brasileira e mundialização da cultura. São Paulo: Boitempo; FAPESP, 2000.

FERNANDES DE OLIVEIRA, Laerte. Em um porão de São Paulo: o Lira Paulistana e a produção alternativa. São Paulo: Annablume: FAPESP, 2002.

GALLETTA, Thiago. Para além das grandes gravadoras: percursos históricos, imaginários e práticas do "independente" no Brasil. Música Popular em Revista, Campinas, ano 3, vol. 1, p.54-79, jul-dez, 2014.

. Cena musical paulistana dos anos 2010: a "música brasileira" depois da internet. São Paulo: Annablume: FAPESP, 2016. 
GPOPAI-USP [Grupo de Pesquisa em Políticas Públicas para o Acesso à informação Universidade de São Paulo]. Uma análise qualitativa do mercado de música no Brasil. São Paulo: ECA-USP, 2010.

HERSCHMANN, Micael. Indústria da Música em transição. São Paulo: Estação das Letras e Cores, 2010.

MACHADO, Cacá. [Orelha de livro]. In: GALLETTA, Thiago. Cena musical paulistana dos anos 2010: a "música brasileira" depois da internet. São Paulo: Annablume/ FAPESP, 2016.

MAKOWSKI, Alexandra. Alexandra Makowski entrevista Romulo Fróes. 15 jun. 2011. Programa Alexandra Makowski entrevista. Disponível em:

<http:/ / www.youtube.com/watch?v=w001tbT4T40\&feature=related $>$. Acesso em: 20 fev. 2018.

MANEVY, Alfredo. Os dez mandamentos do Ministério da Cultura na gestão Gil e Juca. Cadernos CENPEC, n. 7, p.103-115, 2010.

MIDANI, André. Música, ídolos e poder: do vinil ao download. Rio de Janeiro: Nova Fronteira, 2008.

MORELLI, Rita de Cássia. Indústria fonográfica: um estudo antropológico. Campinas: Ed. Unicamp, 1991.

"O campo da MPB e o mercado moderno de música no Brasil: do nacional-popular à segmentação contemporânea". ArtCultura, Uberlândia, v. 10, n.16, p.87-101, jan.- jun., 2008.

MORAIS, Marcos. Mar de músicas. Tribuna de Minas, 8 out. 2013. Disponível em: <http:/ / www.tribunademinas.com.br/mar-de-musicas/>. Acesso em: 20 fev. 2018. 2013.

MULLER, Daniel Gustavo Mingotti. Música instrumental e indústria fonográfica no Brasil: a experiência do selo Som da gente. Dissertação (Mestrado em Música). Instituto de Artes, Universidade Estadual de Campinas, Campinas, 2005.

PINHEIRO, Andréa; PAIVA, Flávio. “Som Zoom: música para fazer a festa”. In: GUERRINI JUNIOR, Irineu; VICENTE, Eduardo (org.). Na trilha do disco: relatos sobre a indústria fonográfica no Brasil. Rio de Janeiro: E-Papers Serviços Editoriais, 2010. p. 41-56.

REVISTA Bravo. Prêmio Bravo! de Cultura 2018. Youtube, 27 mar. 2018. Disponível em: <https:/ / www.youtube.com/watch?v=0mBiYO13aRs>. Acesso em 28 mar. 2018. 
ROUVROY, Antoinette; BERNS, Thomas. “Governamentalidade algorítmica e perspectivas de emancipação: o díspar como condição de individuação pela relação?". Revista Eco-Pos, vol 18, n. 2, 2015.

SESC em São Paulo. Zeca Baleiro, Alexandre Matias e Pablo Miyazawa. Youtube, 19 mai. 2011. Disponível em: < https://www.youtube.com/watch?v=sipVWY4LoO0> . Acesso em: 20 fev. 2018.

VAZ, Gil Nuno. História da música independente. São Paulo: Brasiliense, 1988.

VICENTE, Eduardo. A música popular e as novas tecnologias de produção musical: uma análise do impacto das novas tecnologias digitais no campo de produção da canção popular de massas. 1996. Dissertação (Mestrado em Sociologia). Universidade Estadual de Campinas, Campinas, 1996.

Música e disco no Brasil: a trajetória da indústria nas décadas de 80 e 90. Tese (Doutorado em Comunicações). Escola de Comunicação e Artes, Universidade de São Paulo, São Paulo, SP, 2002.

Z DA QUESTÃO. Banda desenhada, 29 set. 2011. Disponível em: <http:/ / bandadesenhada01.blogspot.com.br/2011/09/z-da-questao.html>. Acesso em: 09 ago. 2013. 